\title{
Rapid communications
}

\section{Cluster of new influenza A(H1N1) CASeS in travellers Returning From Scotland to Greece - COMMUNITY TRANSMISSION WITHIN THE EUROPEAN UNION?}

\author{
T Panagiotopoulos (takis.panagiotopoulos@gmail.com) ${ }^{1,2}$, S Bonovas ${ }^{1}, K_{\text {Danis }}^{1,2}$, D Iliopoulos ${ }^{1}$, X Dedoukou $^{1}$, A Pavli $^{1}$, P \\ Smeti ${ }^{1}$, A Mentis ${ }^{3}$, A Kossivakis ${ }^{3}$, A Melidou ${ }^{4}$, E Diza ${ }^{4}$, D Chatzidimitriou ${ }^{4}$, E Koratzanis ${ }^{5}$, S Michailides ${ }^{5}$, E Passalidou ${ }^{5}$, P \\ Kollaras ${ }^{6}$, P Nikolaides ${ }^{6}$, S Tsiodras ${ }^{1,7}$
}

1. Hellenic Centre for Disease Control and Prevention (KEELPNO), Athens, Greece

2. National School of Public Health, Athens, Greece

3. National Influenza Reference Laboratory for Southern Greece (Hellenic Pasteur Institute), Athens, Greece

4. National Influenza Reference Laboratory for Northern Greece, Second Department of Microbiology, Aristotle University of

Thessaloniki, Thessaloniki, Greece

5. Department of Internal Medicine, Sismanogleio Hospital, Athens, Greece

6. Department of Internal Medicine, AHEPA Hospital, Thessaloniki, Greece

7. University of Athens Medical School, Athens, Greece

\begin{abstract}
On 26 and 27 May, the Hellenic Centre for Disease Control and Prevention in Greece reported two confirmed cases of new influenza $\mathrm{A}(\mathrm{H} 1 \mathrm{~N} 1)$ virus infection in travellers returning from Scotland. The two cases had no apparent traceable links to an infectious source. Herein we report details of the two cases and potential public health implications.
\end{abstract}

\section{Case report}

Case 1

A 21-year old Greek man developed mild influenza-like illness on 24 May while in Edinburgh where he studies. Symptoms included cough and fever $\left(39^{\circ} \mathrm{C}\right)$. On 25 May, he travelled to Athens in Greece and the next day, 26 May, he visited the outpatient department of one of the hospitals designated for influenza $A(H 1 N 1)$ in Athens. The examining physician decided to take a pharyngeal swab, which was tested at the National Influenza Reference Laboratory for Southern Greece, although the patient did not meet the European Union (EU) and national criteria for the new influenza $A(H 1 N 1)$ testing ("case under investigation") [1]. The result of real time PCR was positive for the new influenza $A(H 1 N 1)$ virus (CDC kit). The patient reported no travel history to another place in the past 15 days. To his knowledge, he had no contact with a known case of influenza $A(\mathrm{H} 1 \mathrm{~N} 1)$ or any sick person. However, on 21 May, he met a large number of people, mainly students and attended three student parties in the evenings of 21, 22 and 23 May. Furthermore, he spent a lot of time with his two room-mates and at least two other close friends, one of whom is case 2 . The patient has not developed any complications and is in good condition.

\section{Case 2}

A 20-year old Greek man, a close friend and fellow student of case 1 , developed mild influenza symptoms without complications, with fever $\left(38^{\circ} \mathrm{C}\right)$, mild cough and myalgia, on 24 May. He travelled from Edinburgh to Thessaloniki in Greece on the previous day, 23 May. On 26 May he visited the AHEPA hospital in Thessaloniki, after he had learnt about his friend's (case 1) illness. A pharyngeal swab was taken and tested at the National Influenza Reference Laboratory for Northern Greece, and the real time-PCR test was positive for the new influenza $A(H 1 N 1)$ virus (CDC kit). This patient had also attended many of the same social events as case 1 , including the party of 21 May, but he had not participated in the parties on 22 and 23 May. The last time he met his friend (case 1) was in the morning of 23 May, when he was leaving Edinburgh.

Contact tracing was carried out for close family members, roommates, close friends and social contacts of both the confirmed cases, as well as for flight contacts of case 1 , who was symptomatic during his airway travel. Chemoprophylaxis (oseltamivir) was administered to close contacts in Greece according to the national guidelines. All known contact details were communicated to Health Protection Scotland.

\section{Discussion}

Cases of human infection with influenza $\mathrm{A}(\mathrm{H} 1 \mathrm{~N} 1)$ are currently affecting geographically diverse areas around the world [2-4]. Person-to-person transmission has led to increasing numbers of cases in North America that are attributed mainly to local clusters especially in schools [3]. Nevertheless it appears that in areas with high population density sustained transmission within the community has occurred, mainly in Mexico and the United States, to date $[2-3,5]$. So far, no sustained community transmission has been reported in Europe. However the situation is characterised as rapidly evolving [6] and similar clusters have been reported in Europe [7].

We herein report two cases of influenza $A(\mathrm{H} 1 \mathrm{~N} 1)$ who most probably were not infected from one another, as their symptoms started almost simultaneously and their last person-to-person contact took place about 30 hours before symptom onset. It is 
likely they had a common exposure during one of their several community gatherings in Scotland with no traceable (at this point) link to the source of infection.

The two Greek cases of new influenza $A(\mathrm{H} 1 \mathrm{~N} 1)$ who acquired infection in Scotland raise two possibilities. It is possible that a seeding event from an as yet unidentified traveller from an affected area with widespread sustained transmission (e.g. United States or Mexico) occurred. Whether this exposure happened during one of the gathering events both cases attended or in the community (since both cases had extensive and wide exposure to other community events) is unclear at this point. Secondly, there is a chance that institution-wide transmission has been taking place in the university the cases attend or widespread transmission exists in the community in the specific geographical area in Scotland that has led to the exposure of the two cases.

Several public health implications arise from the cases presented here. Firstly, cases of the new influenza $A(\mathrm{H} 1 \mathrm{~N} 1)$ infection are for the first time confirmed in travellers from one European country to another, with no specific history of exposure to a traveller from Mexico or the United States and no traceable link to the source of infection. Although sustained human-to-human transmission within the country has not been confirmed in Scotland, a number of cases infected within the country have been reported from the United Kingdom [8].

Secondly, if measures for containment of the new virus continue to be implemented for some time in some of the less affected countries to delay spread, there is a need for an efficient mechanism - at an international or at least European level - for updating information about areas with "sustained community transmission".

Thirdly, at this stage of the new influenza $A(\mathrm{H} 1 \mathrm{~N} 1)$ epidemic, community transmission can be established in any country without a known and well identified chain of transmission. This risk increases as we are entering the tourist season and as the number of countries reporting large numbers of confirmed cases is increasing. It is of concern that with the present EU definition of "cases under investigation" [1], and with the practice this definition implies of testing for $\mathrm{A}(\mathrm{H} 1 \mathrm{~N} 1)$ of people with clinical symptoms and travel history to an "affected area" (epidemiological link to a confirmed case or laboratory worker are exceptional at this stage in Europe), we are by definition going to miss cases infected locally in the event of established community transmission without known and identified chain(s) of transmission. For the present period (late spring-summer, minimal seasonal influenza activity), it is probably necessary to modify the present EU definition of "cases under investigation" to also include clusters of patients with influenzalike illness, irrespective of travel history. If this were the case, our patients would have met the criteria for specific influenza $A(H 1 N 1)$ testing.
3. Centers for Disease Control and Prevention (CDC). Swine-origin influenza A (H1N1) virus infections in a school - New York City, April 2009. MMWR Morb Mortal Wkly Rep. 2009 May 8;58(17):470-2.

4. Novel swine-origin influenza $A(H 1 N 1)$ virus investigation team. Emergence of a novel swine-origin influenza A(H1N1) virus in humans. N Engl J Med 2009 [Epub ahead of print]

5. Centers for Disease Control and Prevention (CDC). Map: weekly influenza activity estimates, including novel H1N1 flu. Available from: http://www.cdc. gov/h1n1flu/update.htm

6. European Centre for Disease Prevention and Control. Situation report. Influenza A (H1/N1) infection. 26 May 2009. Available from: http://www.ecdc. europa.eu/en/files/pdf/Health_topics/Situation_Report_090526_1700hrs.pdf

7. Health Protection Agency and Health Protection Scotland new influenza A(H1N1) investigation teams. Epidemiology of new influenza $A(\mathrm{H} 1 \mathrm{~N} 1)$ in the United Kingdom, April - May 2009. Euro Surveill. 2009;14(19):pij=19213. Available from: http://www.eurosurveillance.org/ViewArticle.aspx?ArticleId=19213

8. Health Protection Agency. Swine-lineage influenza A(H1N1). UK update. 27 May 2009. Available from: http://www.hpa.org.uk/web/HPAwebFile/ HPAweb_C/1243322117077

This article was published on 28 May 2009.

Citation style for this article: Panagiotopoulos T, Bonovas S, Danis K, Iliopoulos D, Dedoukou X, Pavli A, Smeti P, Mentis A, Kossivakis A, Melidou A, Diza E, Chatzidimitriou . D, Koratzanis E, Michailides $S$, Passalidou E, Kollaras P, Nikolaides P, Tsiodras $S$. Cluster of new influenza A(H, Pa) cases in travellers returning from scotland to Un Surveill. 2009;14(21):pii=19226. Available online: http://www.eurosurveillance.org/ViewArticle. aspx?ArticleId $=19226$

\section{References}

1. Commission Decision of 30 April 2009 amending Decision 2002/253/EC laying down case definitions for reporting communicable diseases to the Community network under Decision $n^{\circ}$ 21/19/98/EC. 2009/363/EC. Official Journal L 110/58. 01.05.2009. Available from: http://eur-lex.europa.eu/LexUriServ/LexUriServ.do ?uri=0J:L:2009:110:0058:0059:EN:PDF

2. Centers for Disease Control and Prevention (CDC). Outbreak of swine-origin influenza A (H1N1) virus infection - Mexico, March-April 2009. MMWR Morb Mortal Wkly Rep. 2009 May 8;58(17):467-70. 